\title{
DEMONSTRATING EEE RECOVERY FOR REUSE IN A DISTINCT URBAN MINE: A CASE STUDY
}

\author{
Olanrewaju S. Shittu ${ }^{1}$, Ian D. Williams ${ }^{1, \star}$, Peter J. Shaw ${ }^{2}$, Natalie Monteiro ${ }^{2}$ and Rhiannon \\ Creffield ${ }^{3}$
}

\author{
'School of Engineering, Faculty of Engineering and Physical Sciences, University of Southampton, Highfield Campus, Southampton, \\ United Kingdom \\ ${ }^{2}$ School of Geography and Environmental Science, Faculty of Environmental and Life Sciences, University of Southampton, Highfield \\ Campus, Southampton, United Kingdom \\ ${ }^{3}$ Residential Services, University of Southampton, University Rd, Southampton, S017 1BJ, United Kingdom
}

Article Info:

Received:

27 September 2020

Revised:

25 April 2021

Accepted:

28 April 2021

Available online:

30 June 2021

Keywords:

Circular economy

Reuse

Distinct urban mine

Recycling

WEEE

ISB Model

\begin{abstract}
At the heart of the circular economy model is the reorientation of consumer behaviours away from disposing of items before they reach end of their functional life as a step towards resource efficiency and reduction of environmental impacts. One way to facilitate this change is to enable proactive redistribution of electrical and electronic equipment (EEE) with reuse value from urban spaces followed by high quality recycling at end-of-life. We have conducted the first assessment and critical evaluation of a model for the recovery of reusable EEE from a distinct urban mine (DUM) - in this case, a university. The Infrastructure, Service and Behaviour (ISB) model was used as a guide for interventions. Small EEE recovered from two Halls of Residence at the University of Southampton were characterised, visually inspected and sorted. From the items inspected visually, $97 \%$ was reusable and were donated to participating charities for redistribution via reuse/sale. The results show that an ISB Model system designed using choice architecture to recover reusable EEE from a DUM contributes strongly to extending products' lifetimes and promotes circular economy ambitions. The study provides strong evidence of a viable reuse-based recovery system for small EEE in a university DUM and with a potential for replicability at global scale. It is recommended that a carefully planned and tailored system based on the ISB model should be put in place in universities for the recovery and redistribution of reusable EEE (ReEEE) and that recycling is implemented only after practical options for reuse have been exhausted.
\end{abstract}

\section{INTRODUCTION}

Waste Electrical and Electronic Equipment (WEEE) is one of the fastest growing waste streams globally; over 53 million tonnes are generated annually (Forti et al., 2020; Shittu et al., 2021). In 2019, the world generated 53.6 million metric tonnes of WEEE, and only $17.4 \%$ of this was officially documented as properly collected and recycled (Forti et al., 2020). Further growth is expected with the rapid expansion of the digital economy, especially during the COVID-19 pandemic and its anticipated consequences, and the emergence of new technologies in areas such as artificial intelligence, biomedical engineering, renewable energy, space travel, e-textiles and smart agriculture (Shittu et al., 2021). A large proportion of this waste currently comprises personal and consumer electronics such as laptop computers, mobile 'phones and TVs. Around $20 \%$ of WEEE generated globally is recycled but the fate of much WEEE is undocumented (Balde et al., 2017; World Economic Forum, 2019; Forti et al., 2020); tracking the flows of end-of-life electrical and electronic equipment (EEE) is thus challenging. Europe currently has the highest reported WEEE recycling rate at $35 \%$, due to the implementation of the WEEE Directive in European Union (EU) Member States (WEEE Forum, 2019; Forti et al., 2020; Shittu et al., 2021).

The increasing quantities generated have brought WEEE to global attention (Zhang et al., 2019). Studies of WEEE range from the ill-effects on health and environment of poorly-managed WEEE to global recycling practices. There is some, if limited, focus and emphasis on reusability of discarded EEE, aligned with the promotion of a circular economy. Distinct Urban Mining (Ongondo et al., 2015; Pierron et al., 2017; Parajuly et al., 2017; Wilkinson \& Williams, 2019) offers much in this regard. As an example 
of a distinct urban mine, a university campus is analogous to a small city with the potential for a high concentration of discarded EEE (Ongondo et al., 2015), i.e. a distinct space that could be a hub for the recovery of valuable materials and products that would otherwise be thrown away (Cui \& Zhang, 2008; Powell \& Williams, 2019).

Consumerism is escalating as manufacturers create and promote new products, particularly as an outcome of the quest by producers for higher market share. At the same time, growing global affluence has resulted in an increase in "throw-away culture." Consumption and manufacture of short-lived or disposable items rather than durable products that can be repaired inevitably leads to high turnover of items by consumers as consumers opt for newer, often trend-driven items. The linear pattern of buy-use-discard results in the relentless generation of waste that puts immense strain on resources, as there is a constant need to source raw materials to manufacture products to meet increasing demands. Contemporary high-tech EEE such as home entertainment equipment is especially rich in metals and critical raw materials (e.g. rare earth metals and platinum group metals) and constitutes a marked portion of anthropogenic stocks (Massari \& Ruberti, 2013; Golev et al., 2016; Williams, 2016). Demand for consumer electronics is increasing and device usage cycles are shortening, which results in the generation of large quantities of discarded items. This situation has led to an increase in resource efficiency-oriented plans and strategies in the UK and Europe. These range from strategies targeting sustainable consumption such as 'Resource Revolution' (WRAP, 2015) to those promoting reduction in waste generation via product reuse and reparability, such as the EU Circular Economy Action Plan (Circular, 2020). However, some manufacturers appear to dislike these initiatives; Apple Inc., for example, took legal action against a small independent repair shop to the Supreme Court in Norway in order to prevent refurbishment of Apple's iPhones, claiming that its trademark had been "unlawfully appropriated". Apple Inc. won the Norwegian Supreme Court case in June 2020, which could be considered an impediment to reuse. Indeed, this legal decision reinforces maintenance of the status quo (i.e. more recycling and better management of waste disposal) at the expense of societal objectives to reduce, through reuse, the amount of waste being generated and to minimise its potential for harm to human health and the environment. In this respect, this case also raises the importance of recycling specific items (such as small WEEE) and thus highlights the importance of data on product (waste) composition to facilitate end markets for recyclates.

\section{END-OF-USE DECISIONS}

Purchasing decisions are influenced by several factors including, but not limited to, purchasing power (money), lifestyle, peer pressure, contemporary fashion trends, advertising, etc. These decisions often influence the duration of product use (Cox et al., 2013). When a product is no longer wanted or needed (e.g. broken or deemed obsolete, old or out of fashion), the owner could make one of a number of decisions for the fate of the item; decision in this context refers to what is done to the product after it is deemed by the owner to have reached its end-of-life. The decision made could either continue a linear path of production (make-use-dispose) or that of a closed loop. Figure 1 illustrates potential end-of-use decisions and the relationship between each decision.

End-of-use decisions remain strongly influenced by targets relating to recycling. Whilst recycling provides a "feelgood" factor to the public, it does not result in decoupling of consumption and waste generation or the correct application of principles of the waste hierarchy and circular econo-

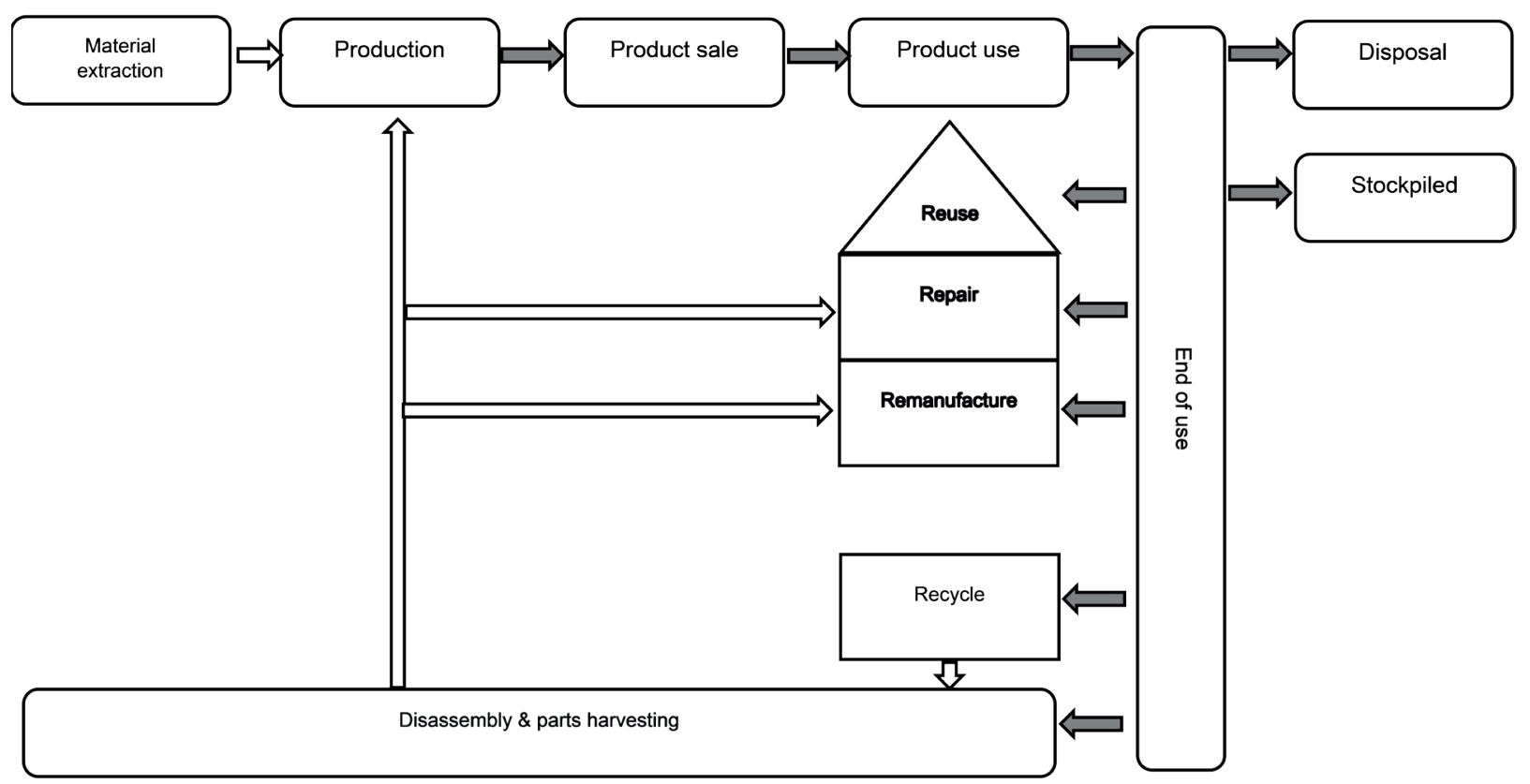

FIGURE 1: Generic product lifecycle with potential destinations after use. Solid arrows indicate product movement; unshaded arrows indicate materials movement. 
my. The decision to dispose, stockpile (a back-up supply retained for future use if/when needed), hoard (stored items that exceed consumers' requirements for use or back-up), reuse or recycle is dependent on various factors including, but not limited to, perceived intrinsic product values, availability and convenience of reuse/recycling channels, ease of repair etc. Behaviour is an important influence in the decision-making at the end-of-use of a product. Decisions promoting a circular economy approach require product owners to behave in a certain manner - such as de-stockpiling/ de-hoarding or buying pre-owned products - to facilitate actions consistent with the desired application of the waste hierarchy (Dunlap \& Jones, 2002; Ongondo et al., 2015, Pierron et al., 2017). Despite the general unpredictability of human behaviour, several theories have been developed to provide insights into human behaviours and the factors influencing them (Darnton, 2008). The Theory of Planned Behaviour (TPB) and the Value-Belief-Norm (VBN) model, for example, have been applied to explain pro-environmental behaviour (Kaiser et al., 2005). Whilst pro-environmental decisions are likely to be influenced by intrinsic motivators such as beliefs, attitudes and norms (Kaiser et al., 2005), pro-environmental behaviours can also be influenced by choice architecture (Thaler et al., 2010), which involves the modification of situational factors to bring about a desired outcome. In their study of distinct urban mining potential of a UK university, for example, Pierron et al. (2017) investigated ownership, stockpiling and disposal of small EEE amongst students and concluded that choice architecture can be deployed to initiate specific and desired outcomes at a product's end of use.

Behavioural theories have been applied when seeking to develop interventions in environmental management. Such interventions are designed such that they address intrinsic and extrinsic barriers to change (Schultz et al., 1995; Timlett \& Williams, 2011). Intrinsic motivation for individuals to engage in pro-environmental behaviours such as reuse and recycling can give rise to a naturally satisfying "warm-glow" effect. Such motivators include personal satisfaction, positive emotions and altruistic motives that benefit the well-being of others. Extrinsic motivators to engage in reuse and recycling may include a desire to conform to social and societal norms, enhancement of personal reputation, praise and financial rewards; several socio-psychological behavioural models have been proposed to explain waste-related behaviours (Williams, 2015). Behavioural change is also influenced by situational factors such as income and infrastructure, although the strength of these factors upon major decisions and actions may be limited (Stern, 2000). Consequently, behavioural change interventions require measures addressing both internal (psychological; intrinsic and extrinsic) and external (situational) factors. Models incorporating both intrinsic and extrinsic factors to explain behaviour in the context of waste and resource management have merit. The Infrastructure, Service, Behaviour (ISB) model, for example, adopts this approach for planning interventions to maximise resource efficiency via consideration of situational and psychological variables (Timlett and Williams, 2011), and has been previously applied to demonstrate the impact of introducing specific and guided interventions in waste and resource management.

\subsection{Higher Education Institutions as circular econ- omy hubs}

Higher Education Institutions (HEls) are viewed as beacons of positive change and promoters of environmental sustainability (Martin and Samels, 2012; Vagnoni and Cavicchi, 2015). This reputation is achieved via knowledge creation and dissemination as well as commitment to sustainable initiatives and policies (Zhang et al., 2011; Tangwanichagapong et al., 2017), ranging from construction of 'green' buildings to carbon-neutral transportation systems and sustainable waste management systems with emphasis on reuse, recycling and resource conservation. With regard to waste management, one step towards achieving sustainability is to consider a HEI to constitute a distinct urban mine (Ongondo et al., 2015). HEls can be viewed as small cities and provide a microcosm of the settlements within which they are situated. People within these $\mathrm{HEl}$ environments, like regular towns or cities, are consumers of goods and services, which make these urban spaces ideal for studying and trialling new initiatives before being implemented at broader scale.

In recent years, resource recovery from waste has been in focus in HEls. There is growing emphasis on diversion of materials from landfill and circular economy thinking based upon application of the waste hierarchy. In a university urban mine, there is potential to divert potentially reusable items during periods when students vacate Halls of Residence accommodation and thereby contribute to efforts to use resources more effectively. One of the categories of items recoverable during such periods is (W)EEE. With WEEE collection rates currently low in most countries and stockpiling of WEEE common, valuable and critical raw materials within these items are potentially lost. WEEE generated globally in 2019 was estimated to contain $£ 50$ billion worth of secondary raw materials (Forti et al., 2020). The loss of such critical raw materials as well as good, functional reusable products emphasizes the need to adopt circular economy approaches, as these will have a positive impact on the future management of (W)EEE. To achieve this aim, an understanding of distinct urban mines is required which will help enhance recovery of reusable EEE as well as resource recovery from WEEE via recycling, leading overall to improved WEEE management. However, for an urban mine to be considered viable, there must be detailed data and information concerning its attributes such as location, size, concentration of materials and resources to be prospected, and products flows.

HEIs in the UK typically provide accommodation for first year students as well as international students enrolled on foundation, pre-sessional and postgraduate courses. According to HESA (2020), approximately $15 \%$ of all enrolled students in UK HEls in were in university accommodation during the 2018/19 academic year (>300,000 students). An academic year is typically made up of 3 terms each of around 10 weeks; the beginning of each term is accompanied by a turnover of students synchronised with teaching schedules. The first term generally comes with the highest level of enrolment in late September, while the summer term sees most student departures in June or July. These 
turnover periods usually result in a high number of departures from student accommodation. The university-maintained facilities thus encounter two (or sometimes three) annual "move-outs" during which students vacate their accommodation (Williams and Powell, 2019); undergraduates move out in early summer and postgraduates (and sometimes pre-sessional language) students move out during early autumn. These periods are usually associated with some products reaching their end of use. The end-ofuse decision made by the owner will be largely dependent on the availability of appropriate (situational) factors. While a departing student is likely to take with them some of their personal possessions, there is always a high likelihood that some products will be discarded, some of which will retain functionality and be reusable. This pattern typically results in the generation of large quantities of discarded items, ranging from bedding, textiles and bric-a-brac to electronics and kitchenware. These regular and predictable surges in the generation of discarded items often lead to littering of streets around student dwellings and tension with the local community. There have been a few attempts by HEls to alleviate this issue. In their review of HEls' reuse schemes, Williams and Powell (2019) highlighted a number of schemes in UK HEls conceived to deal better with moveouts: recovering reusable items results in diversion from landfill, aid to charitable causes and improves relationships with residents and authorities. In several of the schemes reviewed, items deemed in good condition and reusable were donated to charity organisations, sale of which generates income to support the actions of the charities.

The potential recycling value of WEEE is well established in terms of, for example, the potential value of material recycling (Chancerel and Rotter, 2009) and as a secondary metal resource (Oguchi et al., 2011). The concept and potential of urban mining for WEEE within distinct urban spaces (i.e. universities) has been established for WEEE (Ongondo et al., 2015); the collection of both WEEE and end-of-use EEE could be enhanced by the application of choice architecture (Pierron et al., 2017). Relatively few studies, however, have explored the potential for recovery of reusable EEE within distinct urban spaces. Wilkinson and Williams (2020) evaluated the ownership and hoarding levels of home entertainment EEE within a DUM and found a high level of hoarding of devices that can be potentially recovered; the potential for the recovery of reusable items from students in a HEI has been demonstrated but not yet for EEE (Williams and Powell, 2019).

The potential for enhancing reuse in this context can be illustrated by comparing two scenarios, with and without opportunities for EEE reuse. Under a scenario in which HEls provide limited opportunity for the recovery of reusable EEE discarded by students upon departure from university accommodation (Figure 2A), such items are either destined for recycling or commingled with residual waste. Consequently, discarded items with reuse value would be landfilled or recycled: while recycling is a preferred to landfill as an outcome, recycling does not exploit the full value of a still-functional product. A scenario in which opportunities for the recovery of reusable EEE are provided (Figure $2 \mathrm{~B}$ ) requires a targeted intervention and desired behavioural response. Using the ISB model (Timlett and Williams, 2011), suitable interventions can be implemented. A perfect scenario (Figure 2B) for a reuse-based system is one where infrastructure (I), service (S) and behaviour (B) all contribute towards achieving $100 \%$ reuse.
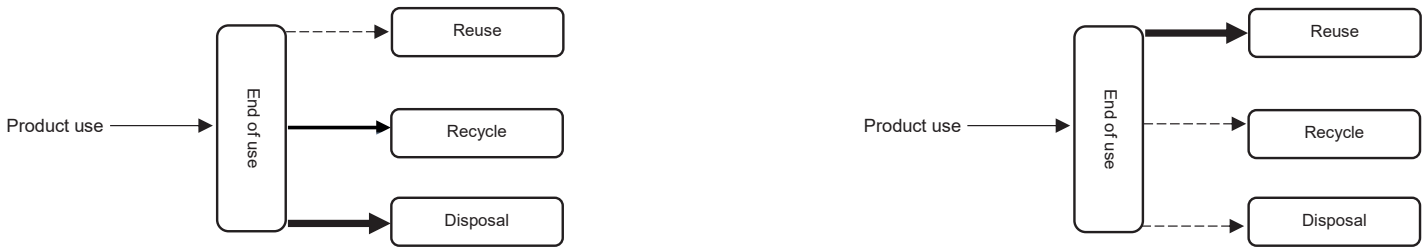

I: little or no infrastructure to facilitate product reuse; products likely to be comingled with residual waste or hibernated

S: no ancillary services for recovery of reusable items

B: willing participants however little service and/or infrastructure likely to inhibit participation in product reuse

I: provision of infrastructure to facilitate product reuse e.g. personal collection bags, temporary storage area

S: availability of ancillary services for recovery of reusable items

B: awareness campaign in form of adverts, notices, themed events etc. to facilitate behaviour change

OUTCOME: Recovery for reuse rate $=0 \%$

OUTCOME: Recovery for reuse rate $=100 \%$

FIGURE 2: Schematic illustration of extreme end-of-use scenarios. Infrastructure (Aspects of the built environment such as buildings, storage bins for recycling); Services (Protocols or systems that enable patterns of behaviour e.g. weekly collection of dry recyclables); Behaviour (How a person undertakes recycling/reuse) (Timlett and Williams, 2011). Panel A illustrates the baseline scenario before intervention. The likely destination for reusable EEE in this scenario is residual waste which goes to landfill with some recycling occurring; $B$ shows the shift to recovery of products for reuse after introduction of an ISB-based recovery protocol aimed at achieving $100 \%$ recovery for reuse. Thickness of arrows indicates likelihood of product destination. 
In this study, we demonstrate the implementation of a reuse-based EEE recovery system conceptualised using the ISB model for the recovery of functional reusable EEE in a university DUM. This is the first assessment and critical evaluation of the potential for recovery and redistribution of reusable EEE from a specific stream in a university urban mine using a reuse-based recovery system. The study makes the case for product reuse as the priority, targeted, most beneficial end-of-use option for sound products as opposed to an inadvertent and unconscious drift towards options that result in giving precedence to product recycling within a DUM. This study presents therefore an evaluation of the potential of a DUM for the recovery of reusable EEE as a priority, with focus on recycling only after practical options for reuse have been fully applied and exhausted. We present reuse as the preferable outcome for end-of-use EEE, thereby keeping products in the system for as long as possible.

The outcomes of the study are as follows:

- Design and implementation of a reuse-based recovery protocol using the ISB model (Timlett and Williams, 2011);

- Estimation and potential value/revenue projection from products recovered for reuse (product and material value);

- Appraisal of collection and recovery protocols; and

- Recommendations on improvements to collection and preparation for reuse of EEE and recycling of WEEE from a DUM.

\section{METHODS}

The study was centred on an assessment of reuse potential in a university urban mine, with focus was on students' Halls of Residence (HoR). HoR experience turnovers of student residents at specific periods, which provide a unique opportunity to investigate the potential for recovery of reusable EEE when students move out of their accom- modation. Also, due to their mixed occupancy, HoR present an ideal study area to assess recovery of items from different groups of students (e.g. undergraduates/postgraduates; home/international domiciled).

The study was conducted in three phases: pre-collection, collection and sorting, and post-collection (Table 1). The pre-collection activities took place in the months leading to the end of summer term of the 2018/19 academic year while the collection phase took place during June, July and September 2019.

\subsection{Study area}

The study took place at the University of Southampton, a large multi-campus university located in the city of Southampton, UK. It has a student population of 24,625 (HESA, 2020), most of whom are based at the main campus in Highfield. The university currently has eight institution-owned HoR offering an array of room types and sizes (University of Southampton, 2019). For this project, two HoR were selected with contrasting populations of student residents (Table 2). As the study set out to encompass a varied and comprehensive mix of students for representativeness, these halls provided representative samples with regard to predominant student groups they accommodate and size and layout.

Mayflower Halls is a large student complex located near Southampton city centre, some $3 \mathrm{~km}$ from the main campus. It has a room capacity of 1,105 . The complex provides accommodation to students at all levels of study (foundation, undergraduate and postgraduate). By contrast, City Gateway is relatively small, located $1.6 \mathrm{~km}$ from the main campus and is exclusively for postgraduate and mature students (21 years or older at the start of their studies). These two HoR vary from layout to types of students accommodated which provides ideal contrast and justifies their selection for the study.

TABLE 1: Project methodology outline including phases and activities.

\begin{tabular}{ll} 
Study Phase & Activities \\
\hline Pre-collection & $\begin{array}{l}\text { Protocol development } \\
\text { Meetings with representatives of residential services and selected charities } \\
\text { Recruitment and protocol briefing of project volunteers }\end{array}$ \\
\hline Collection and Sorting & $\begin{array}{l}\text { Items drop and transportation to central sorting location } \\
\text { Product inspection and data collection } \\
\text { Product redistribution }\end{array}$ \\
\hdashline Post-collection & $\begin{array}{l}\text { Analysis of reuse potential } \\
\text { Material composition analysis (using secondary data) } \\
\text { Process analysis }\end{array}$ \\
\hline
\end{tabular}

TABLE 2: Details of selected Halls of Residence (University of Southampton Residential Services, 2019).

\begin{tabular}{|c|c|c|c|}
\hline Hall of Residence & Maximum capacity & Room types & Dominant student type \\
\hline City Gateway & 364 & $\begin{array}{l}\text { Single rooms (334) } \\
\text { Studio apartments (14) } \\
\text { 1-bed flats (12) } \\
\text { 2-bed flats (4) }\end{array}$ & Postgraduate students \\
\hline Mayflower & 1105 & $\begin{array}{l}\text { Single rooms (1031) } \\
\text { Studio apartments (54) } \\
\text { 1-bed flats (20) }\end{array}$ & $\begin{array}{l}\text { Undergraduate; pre-sessional } \\
\text { students }\end{array}$ \\
\hline
\end{tabular}




\subsection{Protocol development}

The study was based on the assessment of outtakes from two HoR (Mayflower and City Gateway Halls; Table 2) in the University of Southampton using the ISB model (Timlett and Williams, 2011). Increased rate of reuse/ recycling, or indeed any pro-environmental behaviour, requires a balance of situational (infrastructural, service) and psychological (behavioural) factors (see Figure 2). In this context, infrastructure is defined as aspects of the built environment such as buildings, storage bins for recycling; service refers to protocols or systems that enable a pattern of behaviour e.g. weekly collection of dry recyclates; and behaviour refers to how a person undertakes recycling/reuse, influenced by the intrinsic and extrinsic factors discussed above. The methods adopted for this project are guided by the WEEE characterisation study by Parajuly and Wenzel (2017) to evaluate the reuse value and recycling potential of collected household WEEE in Denmark.

This study formed a part of wider initiatives at the University of Southampton to improve institutional resource management (Zhang et al., 2011; Ongondo and Williams, 2011; Pierron et al., 2017; Robinson et al., 2015, 2018), including the collection of reusable items (clothes, homeware, and furniture) for donation to selected charities (Powell \& Williams, 2019). The University of Southampton has committed to an evidence-based cleaner, greener and healthier future, bringing students, staff and local residents together to improve sustainability across our estate (University of Southampton, 2020). In the days leading up to the move-out periods, each collection room at the selected HoR was provided with red plastic bags to enable the deposition of functional but unwanted EEE. Students were instructed to deposit filled bags at designated areas in their accommodation complex. Pamphlets containing information on what was suitable for donation were provided as well as strategically deployed posters and TV screens that displayed relevant information.

There were three survey periods, which were tailored to coincide with the students' departure dates at the HoR in June, July and September 2019. The June period covered students on 38-week accommodation contracts, which is usually the choice for undergraduate students. The majority of students leaving accommodation at this time are final-year undergraduates who have completed their studies, or continuing students seeking accommodation elsewhere. The July period covered students on 40-week contracts whilst the September period involved a mixture of postgraduate (Masters) students and "pre-sessional" students improving their English language skills at a summer school before commencing their subject studies.

\subsection{Participating charities}

The UK charity sector is large and varied, comprising over 160,000 charities with an income of approximately $£ 39$ billion (NCVO, 2014). There are currently several schemes and collaborations between UK HEls and charities involving student donations (Williams and Powell, 2019). The donations help to support causes ranging from education advancement and poverty alleviation to funding medical research. The British Heart Foundation collaborates with over 80 UK universities (Williams and Powell, 2019) via its 'Pack for Good' campaign and the revenue generated from donations helps to fund research into the cure and treatment of heart conditions (BHF, 2020). This charity collects, amongst other items, donated EEE which are sold in their outlets nationwide. The BHF was one of three charities involved in the project (Table 3). Debra is also a national charity which supports epidermolysis bullosa research. Scratch is a regional charity based in Southampton which provides relief effort within the city and surrounding areas and caters for the needs of deprived communities by redistributing reusable items donated such as furniture and small EEE to those in need.

\subsection{Product collection and transportation}

Collection and transfer of donated items occurred over a period of 4-5 days during which the donated bags were transferred to a central location (Wessex Lane Complex). The logistics (collection, transport and sorting) were planned to cater to the needs of the HoR studied. Due to the varied layout and sizes of both halls, transport arrangements differed slightly. For Mayflower Halls, the initial storage area (where students dropped bags) was a large bicycle shed, which acted as a central location for storage before the bags were moved to the sorting area. The arrangement at City Gateway was slightly different due to the lack of a large storage area. Instead, two vehicles were stationed at the hall, which were used to collect the items before transporting to the central sorting area, at which the team of volunteers inspected each bag and sorted items accordingly.

The set-up (Figure 3 ) included a dedicated skip to hold unsorted items, gazebos to shelter project crew and equipment and a $1100 \mathrm{~L}$ storage container (Figure $3 \mathrm{~A}$ ) to hold sorted items awaiting collection by participating charities.

\subsection{Sorting and product characterisation}

A crew of volunteers was recruited to sort the donated EEE over five days in June, July and September 2019. The contents of each bag were visually inspected, weighed using digital scales and graded according to their physical

TABLE 3: Charities involved in the project.

\begin{tabular}{|c|c|c|c|}
\hline Charity & Mission & Coverage & Annual Income $\left(£^{\prime} 000\right)$ \\
\hline British Heart Foundation & Support for cardiovascular research & National & $138,000(2018)^{1}$ \\
\hline Debra & Funding Epidermolysis Bullosa research & National & $16,138(2018)^{2}$ \\
\hline Scratch & Poverty relief & Southampton/Hampshire & $\mathrm{N} / \mathrm{A}$ \\
\hline
\end{tabular}

${ }^{1}$ https://www.bhf.org.uk/what-we-do/where-your-money-goes

${ }^{2}$ https://www.debra.org.uk/downloads/trustees-annual-report-2018.pdf 


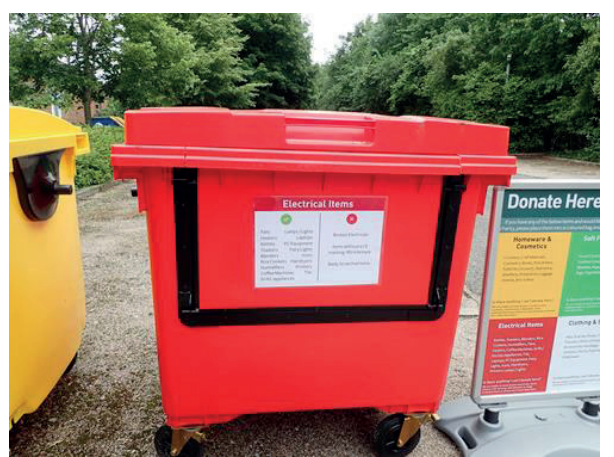

A
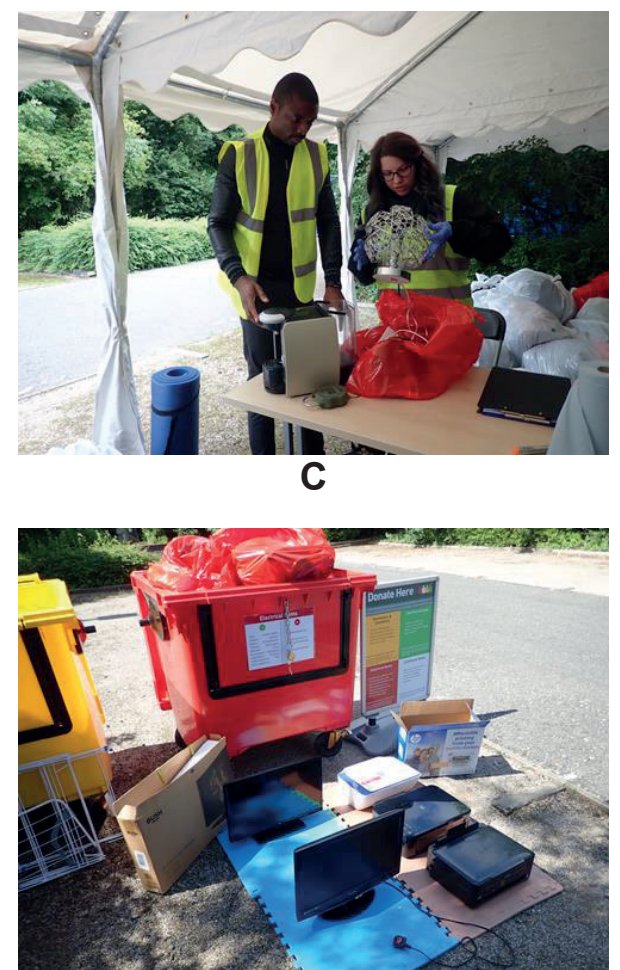

E

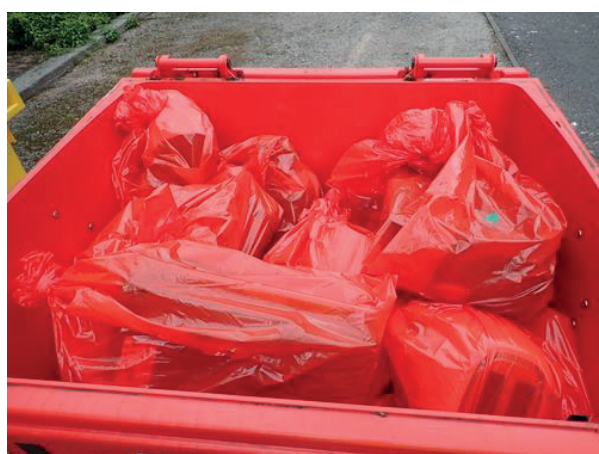

B

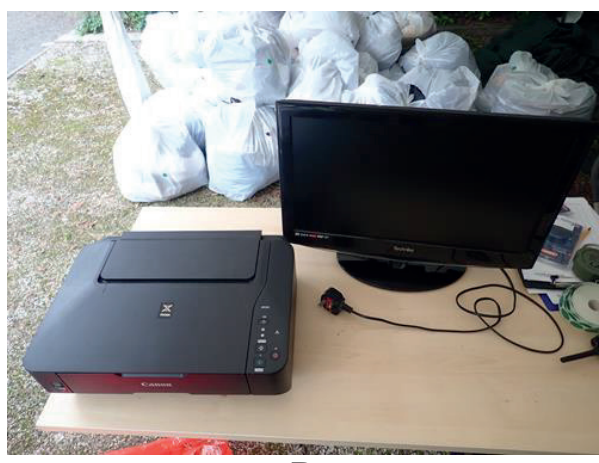

D

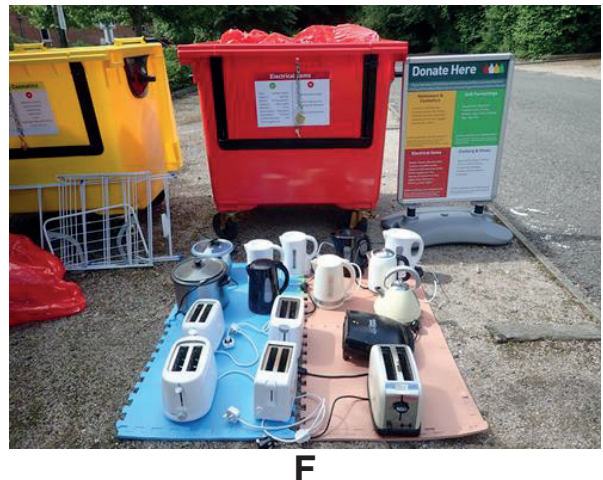

FIGURE 3: A. 1100L storage container used for storage; B. Storage container with bagged contents; C. volunteers sorting and inspecting donated items; D. EEE donation examples: printer and computer display monitor; E. EEE donation examples: ICT devices; F. EEE donation examples: small kitchen appliances.

condition (Table 4). Functionality testing of items was not carried out as it was beyond the scope of the study.

Items that were rejected ("broken"; Table 4) were collected separately for recycling. Each donated bag was also weighed, and numbers of commingled items were recorded to evaluate the success rate of the scheme.

The following information was collected for each inspected item:

\section{Device type;}

- Device category (small kitchen appliances (SKA), small home appliances (SHA), personal care appliances (PCA) and information and communication technology devices (ICT/AV);

- Product brand (where identifiable);

- Product condition (visual inspection of products was carried out and each item was given a grade based on its

TABLE 4: Grading system for product sorting. Product rating determined the fate of each item after sorting with products rated "Good" and "Reusable" recovered for reuse while those rated "Broken" were put aside for recycling. Note that products rated 'Good' and 'Reusable' are ultimately reusable and the distinction between the two ratings is based on the physical condition of item.

\begin{tabular}{l|l} 
Condition & Definitions and examples \\
\hline Good & Good as new; saleable (e.g. a printer with all accessories present; kettle with plug in tact) \\
\hdashline Reusable & Requires repair/component replacement or upgrade (e.g. kettle with a broken plug; LED TV without remote control) \\
\hdashline Broken & Broken/parts missing (e.g. laptop with shattered screen) \\
\hline
\end{tabular}


physical condition (Good, Reusable or Broken; Table 4)

- Product weight (in $\mathrm{kg}$ ). Products that could not be weighed were assigned weights of similarly sized variants/models.

\subsection{Potential for product reuse}

The potential reusability of EEE is largely dependent on the physical condition and functionality of the items collected. Items rated as "Good" (Table 4) are likely to be valued higher due to their condition. Values will also be dependent on other factors such as an item's model, demand and platform/vendor. Estimation of the resale value was based on average prices of commonly-traded EEE, which were obtained from online pre-owned goods trading platforms (www.preloved.com and www.gumtree.com). Prevalent items in the recovery stream were selected for this analysis. In order to account for price variations for each item, 10 price listings were randomly drawn from the aforementioned online platforms to estimate the average price of each item as well as the standard error to account for product price range.

\subsection{Material composition analysis}

In parallel with the evaluation of product reusability and redistribution, a material composition analysis was carried out to estimate the value of materials contained within the EEE collected. This provided a comparison between reuse and recycling scenarios for recovered items. EEE are known to be a rich source of materials such as ferrous and non-ferrous metals (WRAP, 2012; Meloni, 2020). Products that occurred most commonly in the items collected were selected for material composition analysis. For this analysis, secondary data (average material composition of common household EEE) were used (Parajuly and Wenzel, 2017). Minor materials accounting for less than $5 \%$ of an item's weight were excluded in the analysis.

\section{RESULTS AND DISCUSSION}

\subsection{Students' Departures from Halls of Residence}

A total of 1,885 student departures were recorded during the study period (Table 5). Mayflower Hall saw signifi- cantly more departures in June than City Gateway. The reason for this is partly due to size difference: Mayflower Hall accommodates more students (Table 2). City Gateway Hall houses mostly postgraduate students many of whom opt for longer letting contracts (51 weeks) that end in September. July showed the lowest overall departures (199) whilst September saw the highest (1058).

Seventy percent of overall departures during the study period were international students. This contrasts with the demographic profile of the entire university (30\% international students, $70 \%$ home students) (HESA, 2020). September saw the highest international student departures (53\% of total departures) while the lowest count of international student departures was in July ( $0.07 \%$ of total departures). This profile indicates a high proportion of postgraduate international students' departures in this period, many of whom tend to stay longer due to the duration (a full year) of their degree programmes. Pre-sessional students' departures are also numerous at this period. Mayflower Hall saw a high number of home students' departures in June (71\% of Mayflower departures) while a single home student departure from City Gateway was recorded in the same period.

\subsection{Collection output}

In total 128 bags were collected and sorted (Table 6). From these, 447 electrical and electronic items with total weight of $447.67 \mathrm{~kg}$ were inspected and sorted. This equates to approximately $0.24 \mathrm{~kg}$ of donated items per departing student. The June collection saw the highest number of bags (77), despite having the second highest number of departures (661). June also accounted for the highest number of donated items of EEE (234) with a total weight of $242.37 \mathrm{~kg}$. This constituted $52 \%$ of the number of all items collected and $54 \%$ by weight.

With 52 items received, July saw the lowest number of donated items by number and weight $(67 \mathrm{~kg})$. This corresponds with the number of departures as the fewest departures (67) at this time. However, July saw the highest collection per student departure at $0.52 \mathrm{~kg} /$ student compared with $0.39 \mathrm{~kg} /$ student and $0.19 \mathrm{~kg} /$ student for June and September, respectively. The overall average collection rate was $0.24 \mathrm{~kg} /$ student.

TABLE 5: Student departures for Mayflower and City Gateway Halls in 2019.

\begin{tabular}{|c|c|c|c|c|}
\hline Hall of Residence & Month & Home (UK) students & International students & Total \\
\hline \multirow{3}{*}{ Mayflower } & June & 437 & 177 & 614 \\
\hline & July & 30 & 77 & 107 \\
\hline & September & 14 & 795 & 809 \\
\hline \multirow{3}{*}{ City Gateway } & June & 1 & 13 & 14 \\
\hline & July & 40 & 52 & 92 \\
\hline & September & 41 & 208 & 249 \\
\hline
\end{tabular}

TABLE 6: EEE donation bag collections from Mayflower and Gateway halls of residence in 2019.

\begin{tabular}{c|c} 
Month & Number of donation bags collected \\
\hline June & 77 \\
September & 19 \\
Total & 32 \\
\hline
\end{tabular}


TABLE 7: Numbers of items collected during surveys in 2019 and their condition (see Table 4).

\begin{tabular}{c|c|c|c|c} 
Month & Number of items & Good & Reusable & Broken \\
\hline June & 234 & 101 & 119 & 14 \\
\hline July & 52 & 21 & 28 & 3 \\
\hline September & 161 & 106 & 55 & 0 \\
\hdashline Total & $\mathbf{4 4 7}$ & $\mathbf{2 2 8}$ & $\mathbf{2 0 2}$ & $\mathbf{1 7}$ \\
\hline
\end{tabular}

A summary of the items inspections and their condition is presented (Tables $7 \& 8$ ). Of the 234 items inspected in June, 101 items were rated as "Good" (43\%) while 14 items were rated as "Broken" (6\%). A similar trend was recorded in July with 21 out of 52 items rated as "Good" (40\%) while $54 \%$ of items inspected were rated as "Reusable". September saw the highest percentage of items rated as "Good" (66\%; 106 out of 161 items inspected).

The EEE collected were categorised into: SHA, SKA, ICT and PCA based on the internationally recognised categorisation framework by Forti et al. (2018). The volumes collected for each category varied, however, a greater volume
TABLE 8: Weights of items collected during surveys in 2019 and their condition (see Table 4).

\begin{tabular}{c:cccccc} 
Month & Weight (kg) & Good & Reusable & Broken \\
\hline June & 242.4 & 100.7 & 132.2 & 9.5 \\
\hdashline July & 55.3 & 22.4 & 30.8 & 2.1 \\
\hdashline September & 150 & 90.8 & 59.2 & 0 \\
\hdashline Total & $\mathbf{4 4 7 . 7}$ & $\mathbf{2 1 3 . 9}$ & $\mathbf{2 2 2 . 2}$ & $\mathbf{1 1 . 6}$ \\
\hline
\end{tabular}

of SHA was collected in June (40\%) and September (35\%) than other categories. This category includes items such as desk lamps, fans and extension cables. June also saw a high proportion of SKA items (37\%). However, the highest proportion of SKA was recorded in July (Figure 4). Approximately $61 \%$ of all items collected during this period were SKA. Regarding ICT, 41 and 43 devices were collected in June and September respectively, including some high-value devices in good condition: three LED TVs and six printers. The September collection also included higher-value ICT items: six printers (two Good and four Reusable) and six laptops (five Good and one Reusable).

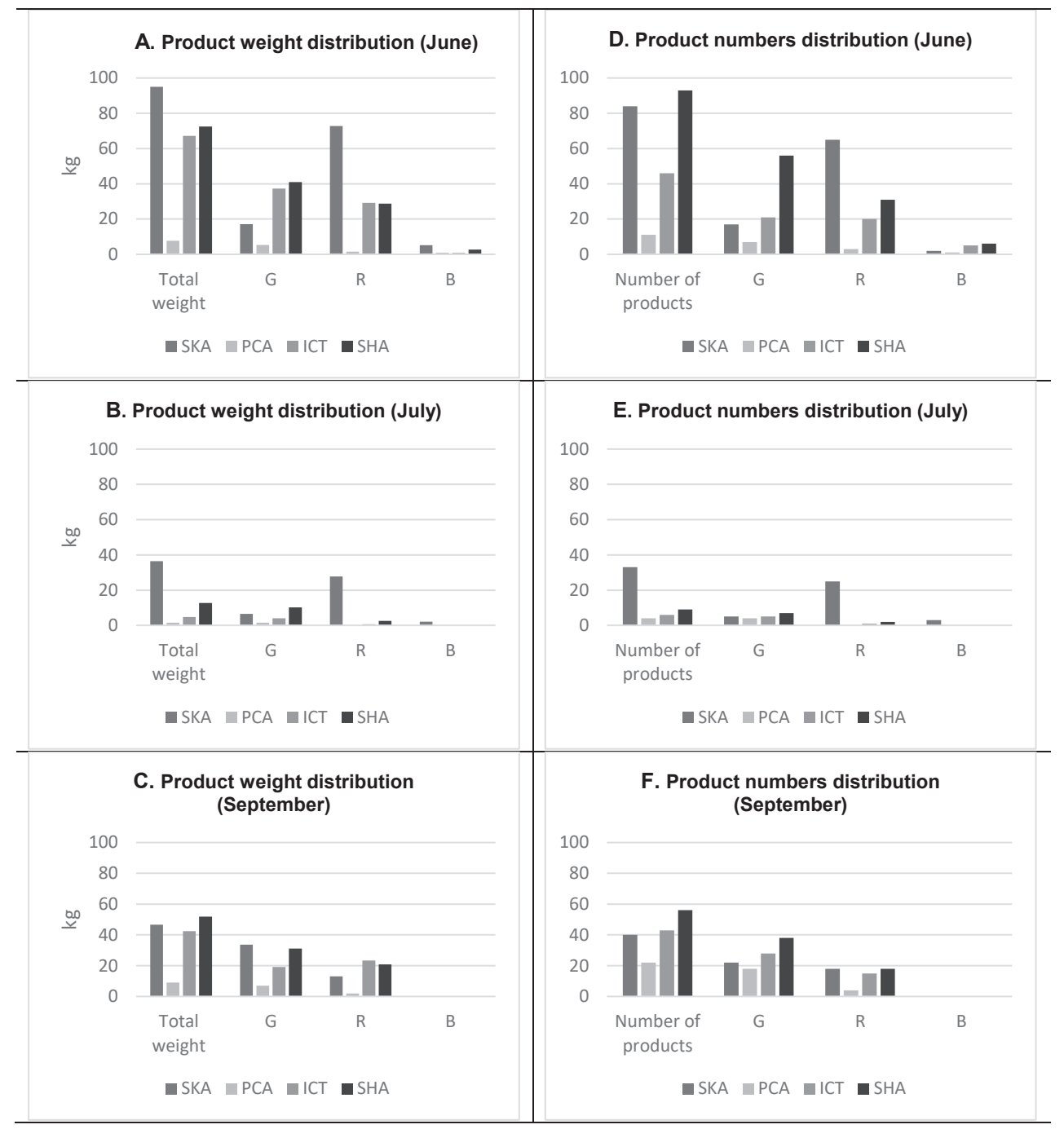

FIGURE 4: Distributions of collected and assessed items and associated grading (see Table 4). 


\subsection{Reuse potential}

A total of 430 out of 447 items collected during the project were either rated as "Good" or "Reusable". For each category, over $90 \%$ of the items inspected were rated either as "Good" or "Reusable" (Table 9). SKA and SHA products constituted most of the items collected (152 items per category), each with reusability of $97 \%$ and $96 \%$ respectively. Though the total number of items collected in PCA category was the lowest, this category had the highest reuse rate (Good or Reusable items) at just over $97 \%$. Hair grooming products such as hair dryers and stylers featured prominently in this category.

The resale value was estimated for selected items collected during the study. The potential resale value of the items selected is presented in Table 10.

The resale value of an item is dependent on its physical condition and functionality. The resale values (Table 10) show a range of values of similar items from reuse platforms. From the analysis, the items were estimated to be worth between $£ 2584$ and $£ 3758$. We note that this estimate is for a subsample of items collected ( 36\%) and the items collected and assessed for this were from only two HoR in a single HEl (University of Southampton).

\subsection{Material composition}

A material composition analysis was carried out to estimate the quantities of materials contained in the items collected. EEE are a rich source of materials such as ferrous metals, non-ferrous metals and plastics (WRAP, 2012; Meloni, 2020). A selection of products was analysed based on their prevalence in the stream of items collected (Tables 11 and 12). Products rated as "Broken" were also included for the material composition analysis.

Using compositional analysis data (Table 11), the material composition of a selected group of EEE from the collection was estimated (Table 12). These five products accounted for $36 \%$ of the 447 items collected and sorted. From the analysis, $162.6 \mathrm{~kg}$ of these four materials were recovered ( $\mathrm{Fe}, \mathrm{Cu}, \mathrm{Al}$ and plastics) and constituted $94 \%$ of the total weight of these five products. Table 13 presents the value of metals in the prevalent items evaluated. The residual weight is for materials with trace quantities which were not considered in the analysis. Plastics form the bulk of material component (55\%) which is expected as small EEE are typically made of over 15 different plastic polymers (Martinho et al., 2012). Copper is the least abundant material fraction in the EEE sampled though at $\$ 5,763 /$ tonne (LME, 2020), it is the most valuable material per unit weight.

\subsection{Variation in products collected}

The study demonstrates the substantial potential for recovering small EEE for reuse and recycling from students departing from university HoR. With 447 items weighing approximately $450 \mathrm{~kg}$ (Tables 7 and 8) collected from just two HoR in one academic year, there is a huge potential for

TABLE 9: Product grading by category. Items in each category assessed and graded using grading system adopted (see Table 4). Reusability (\%) is the proportion of assessed items that were reusable (products rated 'Good' or 'Reusable').

\begin{tabular}{c|c|cccc}
\multicolumn{1}{c|}{ Product category } & Total & Good or Reusable & Reusability (\%) & Broken \\
\hline SKA & 157 & 152 & 96.8 & 14 \\
\hline PCA & 37 & 36 & 97.2 & 3 \\
\hline ICT & 95 & 90 & 94.7 & 0 \\
\hline SHA & 158 & 152 & 96.2 & 17 \\
\hline
\end{tabular}

TABLE 10: Estimated product reuse value of select items collected. Items selected featured heavily in stream assessed. Resale value estimates are based on average price of similar products on online resale platforms; \pm standard error of the mean

\begin{tabular}{|c|c|c|c|}
\hline Item & Average price (pre-owned) (£) & Number of Good or Reusable items collected ) & Estimated potential resale value $(\mathfrak{f})$ \\
\hline Iron & $9.70 \pm 2.00$ & 14 & $108-164$ \\
\hline Kettle & $9.40 \pm 0.80$ & 74 & $636-755$ \\
\hline Lamp & $21.20 \pm 5.00$ & 59 & $956-1546$ \\
\hline Toaster & $8.80 \pm 1.20$ & 39 & $257-390$ \\
\hline Printer & $51.30 \pm 9.50$ & 12 & $502-730$ \\
\hline Hair dryer & $7.45 \pm 1.20$ & 20 & $125-173$ \\
\hline Total & & 218 & $2584-3758$ \\
\hline
\end{tabular}

TABLE 11: EEE average material composition (\%). Source data from Parajuly and Wenzel (2017).

\begin{tabular}{|c|c|c|c|c|}
\hline Product & Iron (\%) & Copper (\%) & Aluminium (\%) & Plastic (\%) \\
\hline Iron & 21.6 & 7.1 & 19.3 & 51.0 \\
\hline Kettle & 4.7 & 5.6 & 22.0 & 62.2 \\
\hline Toaster & 36.8 & 3.3 & 27.3 & 30.4 \\
\hline Printer & 26.1 & 1.8 & 0 & 60.2 \\
\hline Hair dryer & 15.7 & 15.3 & 0 & 63.5 \\
\hline
\end{tabular}


TABLE 12: Number and average material composition $(\mathrm{kg})$ of select products collected.

\begin{tabular}{|c|c|c|c|c|c|c|}
\hline Product & Number collected & Total weight (kg) & Iron (kg) & Copper (kg) & Aluminium (kg) & Plastic (kg) \\
\hline Iron & 14 & 10.3 & 2.22 & 0.73 & 1.99 & 5.25 \\
\hline Kettle & 77 & 52.5 & 2.47 & 2.94 & 11.55 & 32.56 \\
\hline Toaster & 39 & 49.1 & 18.07 & 1.62 & 13.40 & 14.93 \\
\hline Printer & 12 & 52.2 & 13.62 & 0.94 & 0 & 31.42 \\
\hline Hair dryer & 21 & 9.4 & 1.48 & 1.44 & 0 & 5.97 \\
\hline Total & 163 & 173.5 & 37.86 & 7.67 & 26.94 & 90.13 \\
\hline
\end{tabular}

TABLE 13: Material value of subsample of items (see Tables 11 and 12). Metal values based on London Metal Exchange average prices per tonne at three months forward as of 18/6/2020 (LME, 2020).

\begin{tabular}{|c|c|c|c|}
\hline Metal & Weight (kg) & f/tonne* & Material value $(\boldsymbol{(})$ \\
\hline $\mathrm{Fe}$ & 37.86 & 212 & 80.3 \\
\hline $\mathrm{Cu}$ & 7.67 & 4,591 & 35.2 \\
\hline $\mathrm{Al}$ & 26.94 & 1,274 & 34.3 \\
\hline Total & 72.47 & & 149.8 \\
\hline
\end{tabular}

*Metal values converted to $£$ sterling using OANDA currency converter (Oanda, 2020)

the recovery of reusable from this stream if more HoR are involved. The study observed the peak month for collection to be June. This is despite more students departing in September (Table 5). The higher proportion of 'Good' items recorded in September may be indicative of better information assimilation by the students on type and condition of items suitable for donation as the students that moved out at this time had more time to prepare.

Small kitchen appliances and small household appliances constituted the bulk of overall EEE recovered (157 and 158 items respectively out of a total of 447 items). This suggests that such items are purchased or brought in by students moving into halls at high numbers. While the HoR studied provide basic kitchen and household items for shared use, the high level of recovery of items in these categories suggests that students opt to bring in or purchase their own. This may be more common amongst international students ( $70 \%$ of total departures) who may have brought with them items like kettles, sandwich makers; some of the product brands were from outside the UK. While it is difficult to attribute items donated to individual students, it is safe to assume, due to large percentage of international students in the sample population, that departing international students are more likely to donate items deemed excess, making them a potentially viable group to target for a reuse scheme (Williams and Powell, 2019).

The present study observed a high level of compliance from students regarding the condition of items collected; only a small fraction of items collected did not meet criteria as specified in the guidance and were deemed unsuita- ble for reuse. The majority of these unsuitable items were received in June (Table 14) and were mostly SHA. The level of compliance resulted in a contamination rate of less than $5 \%$ during each month of collection (with an overall contamination rate of $2.6 \%$ ). These products, while not available for reuse, retain resource value and material recovery can occur via recycling.

The HoR studied provide facilities for WEEE recycling in the form of storage bins and yards which may have contributed to the low rates of contamination since students already have an option to recycle broken/non-functional EEE. Studies have shown that without such facilities, such items are likely to be disposed of in general waste (Ongondo \& Williams, 2011; Pierron et al., 2017). Pierron et al. (2017) also observed high likelihood of end-of-use PCA disposal as opposed to being recycled. This may explain the low prevalence of PCA collection observed during this study.

\subsection{Reuse and recycling potential}

The UK has over $150 \mathrm{HEl}$ and each $\mathrm{HEl}$, in principle, is potentially an urban mine rich in items and resources that can be reintroduced into the circular economy (Pierron et al., 2017). According to the Higher Education Statistics Agency (2020), 351,605 students live in university-owned HoR/accommodation (2018/2019 data) across the UK. Assuming a reusable EEE recovery rate of $0.24 \mathrm{~kg} / \mathrm{student}$ as observed in this study, there is a UK-wide potential for recovery of 84 tonnes of EEE for reuse annually. This potential value excludes other students living outside HoR who constitute the majority; of the over 2 million students

TABLE 14: Contamination rate of EEE collection (Contamination rate: proportion of contaminants in total items collected i.e. contaminants $(\mathrm{kg}) /$ total items $(\mathrm{kg})$ as \%. Contaminants in this study comprise items rated 'Broken').

\begin{tabular}{c|c|c|c|c} 
Month & Total weight $\mathbf{( k g )}$ & Weight (Good \& Reusable) $\mathbf{( k g )}$ & Weight (Broken) $\mathbf{( k g )}$ & Contamination rate (\%) \\
\hline June & 242.4 & 232.9 & 9.5 & 4.1 \\
\hline July & 55.3 & 53.2 & 2.1 & 4.0 \\
\hline September & 150 & 150 & 0 & 0 \\
\hline Overall & 447.67 & 435.87 & 11.6 & 2.6 \\
\hline
\end{tabular}


enrolled at universities during 2018/19 academic year, only $17.5 \%$ students resided in HoR (HESA, 2020).

The observed subsample of items (Table 10) was estimated to yield potentially an estimated resale value of $£ 2,600-£ 3,700$. This equates to $£ 1.30-£ 1.90$ per student (from a student population of 1,885). Assuming that this figure is broadly representative of UK university students, this represents a monetary value of up $£ 485,000$ - $£ 690,000$ for all students living in UK university accommodation nationwide in the 2018/19 academic year. Scaling this up for total student population, assuming the same monetary value per student, and that students in other accommodation undergo periodic clear-out, the student population at University of Southampton (24,625 students) and UK universities (2,383,970 students), the monetary potential is up to $£ 46,000$ and $£ 4,500,000$ respectively (using a value of $£ 1.90$ per student). On the other hand, the material value of the same subsample was estimated to be $£ 27,942$ for a student population of 361,605 and $£ 189,453$ for entire student population in the UK. These data suggest a high potential for reuse as these estimates cover a subset of all items recovered and assessed. This potential could be higher considering that the products, apart from their reuse value, also possess material value which can be exploited via recycling at their end of life. While resale value is likely to plummet with each product usage cycle, the materials contained (especially metals) will retain their value.

\subsection{Process analysis}

Schemes involving donation of unwanted and/or end of use items with reuse value is commonplace in UK HEls. Schemes such as 'Shift your Stuff' organised by the Student Union at the University of Southampton have been planned to coincide with the departure periods of students and encourage the donation any unwanted items when they move out. Schemes run in the past by Students' Union collected items such as clothing, homeware and other brica-brac but excluded collection of reusable EEE. The present study is the first of its kind that specifically studied the outcome of source-segregated EEE donations. Comingling with broken EEE was minimal as observed in the contam- ination rate (Table 12), indicating that information provided was largely understood. As stated previously, the study was preceded by a period of information disseminated using different media, including strategically-located posters and pamphlets (Figure 5).

The study had three major components; collection/recovery of EEE from departing students, sorting and characterisation of the items received and the redistribution which involved select charities (Figure 6). Interventions made for the collection/recovery component included provision of bags as well as temporary storage areas to hold the EEE. With this, the protocol differed between the two HoR studied. Mayflower Halls has a large sheltered bicycle shed which doubled as a temporary storage (Infrastructure aspect of ISB model) hold for the EEE collected. The situation was different at City Gateway Hall, which lacks an adequate storage area; instead, the collected items were stored temporarily in vans. This is an example of infrastructure differences which required different interventions as postulated by the ISB model (Timlett \& Williams, 2011).

The EEE collected went through a process of screening and sorting. The activities could not be feasibly carried out at the sites of collection (HoR) for logistical reasons. While Mayflower Halls complex has a storage space which, in principle, could have been used for product sorting, City Gateway lacks such a facility and the small number of volunteers recruited for the project were necessarily co-located. As a result, all items collected were moved to another location where sorting took place (Figure 2).

The study recorded a high reuse rate overall (Table 9). The assessment of products received (Table 4) was necessarily based on visual inspection. Several items received required cleaning while some others were missing minor components. However, a more robust assessment such as functionality testing was not carried out as it was beyond the scope of the project. Whilst there is merit in undertaking robust functionality tests (Parajuly and Wenzel, 2017), addition of a testing stage to the protocol would incur additional resources and costs. It is probable that a functionality test would have resulted in a higher rejection/contamination rate. An idealised scenario would involve recovery and
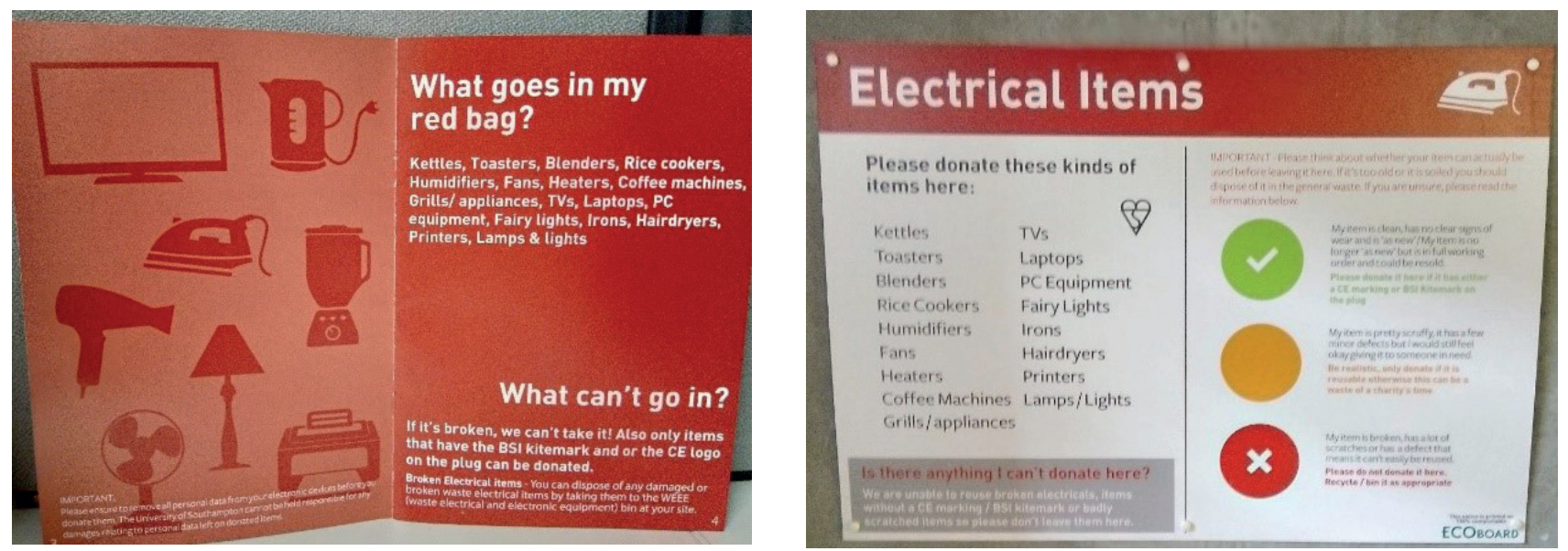

FIGURE 5: Some examples of media used to influence behaviour change by providing information on the project (Source: University of Southampton Residential Services, 2019). 


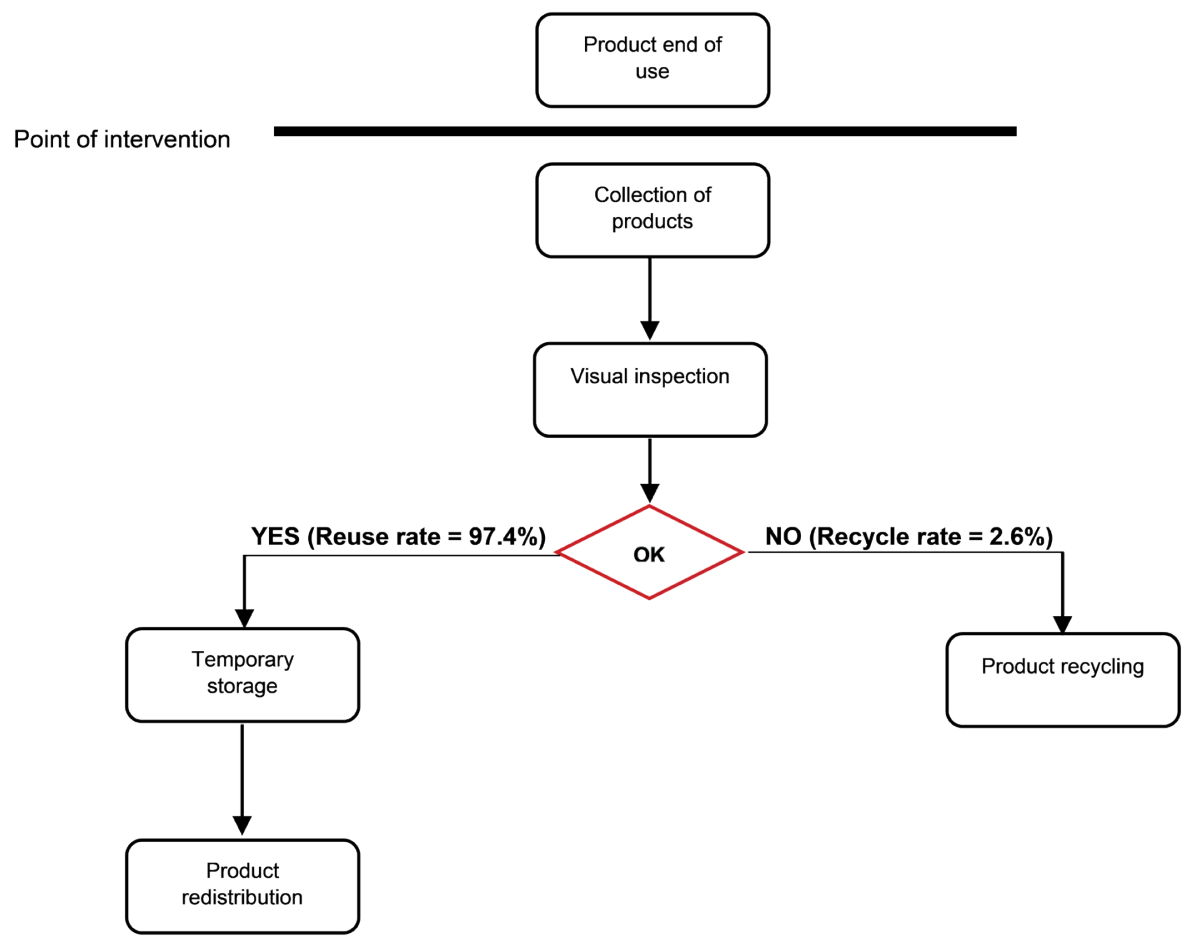

FIGURE 6: Project protocol and processes including the interventions made using ISB model (I: temporary storage; S: collection and inspection of products; B: products are redirected and made to pass through the system which recovers items with residual reuse value).

movement of products and materials within a closed loop (Figure 7) together with ancillary services for product testing, repair/upgrade, storage and redistribution. However, a recovery system based on reuse can still accommodate items not deemed for this purpose (reuse) as such items still possess some value and can be recycled.

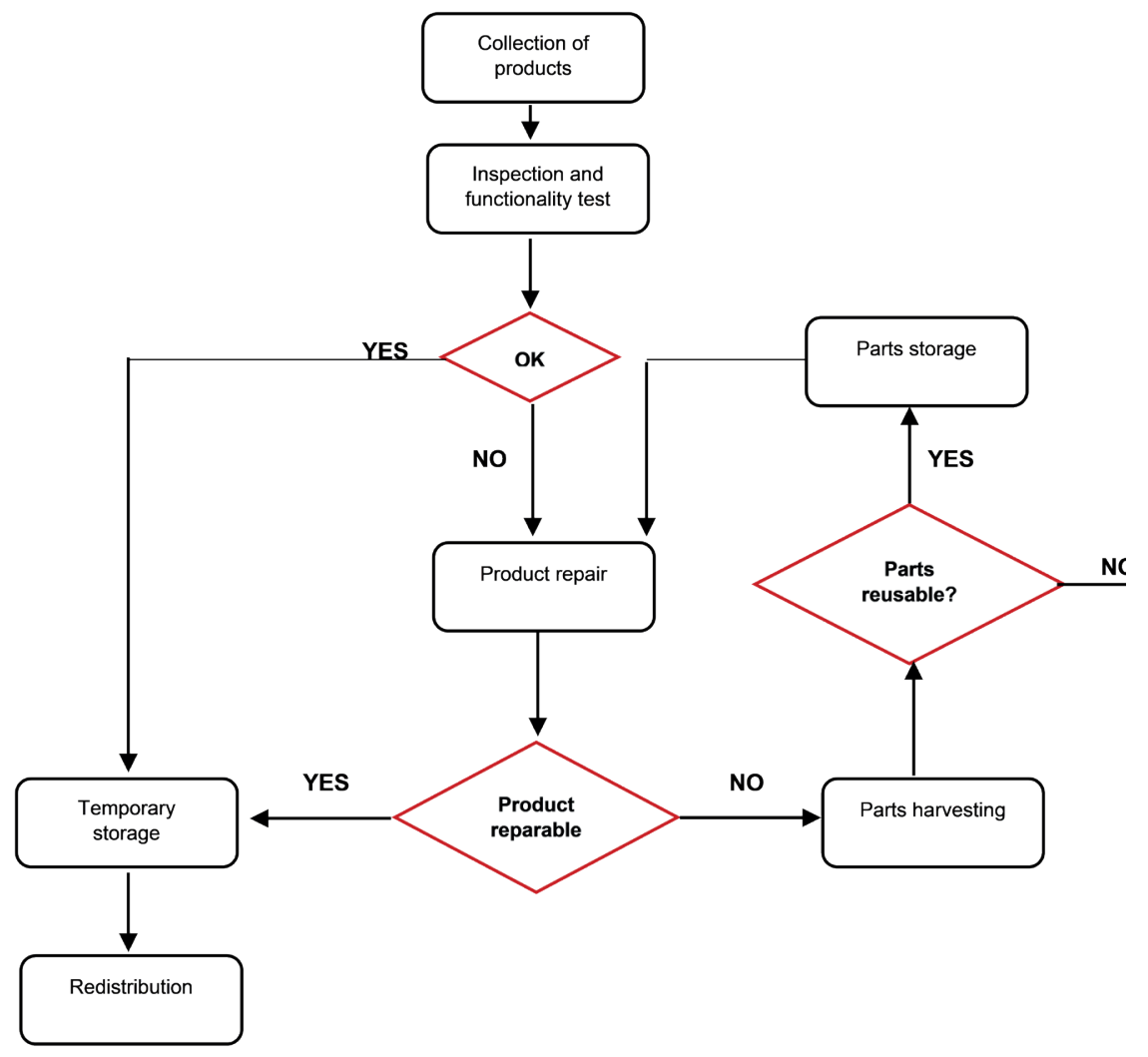

FIGURE 7: A reuse-based collection and redistribution protocol for EEE recovery in a university DUM including the relevant ancillary processes. 
TABLE 15: Cross-sectoral benefits of a reuse-based EEE recovery system.

\begin{tabular}{|c|c|c|}
\hline Stakeholder & Benefit & Benefit category \\
\hline Charities/NGOs or other recipients & Receipt of good quality reusable items at little cost; redistribution of items & Economic; Social \\
\hline Universities/HEls & Lower disposal expenditure; enhancement of 'green' credentials & Economic; Environmental \\
\hline Students & 'Warm glow' (intrinsic factor) of contributing towards environmental sustainability & Psychological \\
\hline Waste/environmental manager & Carbon savings, resource conservation; circularity & Environmental; Economic \\
\hline
\end{tabular}

For this study, the involvement of charities proved effective in the redistribution and reuse of products collected. As previously noted, there are national charities that have partnered with HEls in schemes involving product recovery and redistribution, diverting reusable products from landfill or recycling. Future collaborations in such schemes, as demonstrated in this project, will yield positive environmental, social and economic impacts. Examples of such impacts are highlighted in Table 15.

These benefits are universally derivable irrespective of location. While this study was undertaken in the UK, adoption of a similar strategy in similar settings (i.e. HEIs) elsewhere will potentially yield similar outcomes. The UK, due to its well-established charity sector, provides a platform through which recovered reusable products can be redistributed for resale/reuse. Similar organisations elsewhere in form of NGOs (non-governmental organisations) are potential benefactors and can perform similar roles. A key factor of the reuse-based recovery system is the transient nature of university/HEl student population. Due to periodic turnover of students, there will be predictable and repeated opportunities for recovery of reusable EEE from departing students or those changing accommodation. While the frequency of this annual turnover within an academic year may vary from country to country, this unique factor allows for global replicability of the reuse-based EEE recovery system.

\subsection{Future perspectives}

Circularity provides a means to keep products (including EEE) and materials in use for extended periods and presents an opportunity to reduce negative environmental impacts. A successful implementation of the circular economy model will be dependent on factors such as product design and reverse logistics as well as having an enabling environment (Meloni, 2020). Product reuse can become a mainstay, with adequate interventions, from production to end of use. Products designed with ease of disassembly and/or repair are likely to be in a closed loop longer as such products can retain functionality for longer periods, potentially changing owners during their lifetime. Going forward, interventions such as using modular designs would become crucial for incorporating circular economy principles in product design.

Reverse logistics is another crucial element of the circular economy model. As this study has shown, providing the means to recover and redistribute reusable items can provide economic, societal and environmental gains (Table 14). With organisations such as charities available to absorb and aid redistribution of such items, they provide solutions within a circular economy by either selling or do- nating to potential new owners. As noted by Meloni (2020), movement of products between different categories of users, e.g. high-end users to lower/emerging users, ensures that products can be made available to cater to the needs and constraints of different users during their lifetime. While such movements have been labelled as 'dumping,' particularly when involving product movement from developed to developing countries, providing a high-quality reuse standard for pre-owned items would ensure that such products undergo rigorous testing and certification before being moved on to new owners.

Attitudes towards pre-owned EEE are a potential barrier to reuse. Improving perceptions of reuse could be a significant step towards circularity. Again, a high-quality reuse standardisation and certification provides an opportunity to alter perceptions. This post-use quality assurance system such as that used in studies such as Hickey et al. (2014) and Dietrich (2014) involves testing, upgrading and certifying pre-owned EEE before redistribution to new owners. A system such as this provides a 'seal of quality' which will help alter perception on pre-owned but functional EEE.

\section{CONCLUSIONS}

This study clearly provides evidence that a reuse-based recovery system for small EEE significantly increases the urban mining potential of a university DUM while creating an avenue to provide a platform for extending the life time of small EEE. While there were logistical challenges, the project demonstrates a workable proof-of-concept for a reuse-based recovery and redistribution system within a university DUM.

The study presented product reuse as a priority for end-of-use EEE for sound but unwanted products within a DUM as opposed to an inadvertent and unconscious drift towards less desirable options. It provides an important insight into the significant potential for recovering reusable small EEE from a DUM, in this case, students within a university urban mine. The study presents, for the first time, data on recovery of reusable small EEE from departing students from university HoR. Through applying a protocol informed by the ISB model (Timlett \& Williams, 2011), the transfer of items from donors (students) to beneficiaries (participating charities) has been demonstrated to support the case for reuse as the preferred end-of-use decision for products with good functionality and, in so doing, result in positive environmental, economic and social impacts. As this was a demonstration project, the potential for impact if replicated nationwide is highly significant in terms of increased diversion from landfill, resource efficiency, materials recovery at end-of-life, reduction of adverse environmental effects, and social and economic benefits. This 
study also highlights the role individual young people can play when they act in concert for societal benefit and the global replicability of the reuse-based system as a viable route to circularity of EEE.

This project was aided by a communication campaign, which elicited a positive behavioural response from the students, as well as provision of necessary infrastructure and service. This demonstrates that the ISB model can bring about desired changes in addressing waste management issues. It is recommended that the adoption of similar systems in universities and other HEls within the UK and globally has tremendous potential to divert several tonnes of reusable EEE from landfill as well as providing social and economic benefits.

\section{ACKNOWLEDGEMENTS}

The authors would like to thank Residential Services at the University of Southampton, particularly Dave Francis, for providing support and access to the study area. We also acknowledge and thank volunteers Amal Alamand, Zora Pekarkova, Hannah Whalley, Janice Abalo, Haoyang Peng and Yixuan Wang who aided during fieldwork.

\section{REFERENCES}

Baldé,C.P., Forti,V., Gray,V., Kuehr,R. and Stegmann,P. (2017).The Global E-waste Monitor - 2017, United Nations University (UNU). International Telecommunication Union (ITU) \& International Solid Waste Association (ISWA), Bonn/Geneva/Vienna.

British Heart Foundation (2020). BHF: what we do. (Online) Available at: https://www.bhf.org.uk/what-we-do (accessed 20/2/2020)

Chancerel, P., and Rotter, S. (2009). Recycling-oriented characterisation of small waste electrical and electronic equipment. Waste Management, 29, 2336-2352

Circular (2020). European Commission adopts new Circular Economy Action Plan. (Online) Available at: https://www.circularonline. co.uk/news/european-commission-adopts-new-circular-economy-action-plan/ (accessed 20/3/2020),

Cox, J., Griffith, S., Georgi, S., and King, G. (2013). Consumer understanding of product lifetimes. Resources, Conservation and Recycling, $79,21-29$.

Darnton, A. (2008). Reference Report: An overview of Behaviour Change Models and their Uses. A Report to the Government Social Research Unit. Available at: http://www.gsr.gov.uk/downloads/resources/behaviour_change_review/reference_report.pdf

Dietrich, J., Becker, F., Nittka, T. et al. (2014). Extending product lifetimes: a reuse network for ICT hardware. Waste and Resource Management, 167 (WR3), 123-135.

Forti V., Baldé C.P. and Kuehr R. (2018). E-Waste Statistics Guidelines on Classification, Reporting and Indicators. Edited by ViE - SCYCLE United Nations University. Bonn, Germany.

Forti V., Baldé C.P., Kuehr R., Bel G. The Global E-waste Monitor 2020: Quantities, flows and the circular economy potential (2020). United Nations University (UNU)/United Nations Institute for Training and Research (UNITAR) - co-hosted SCYCLE Programme, International Telecommunication Union (ITU) \& International Solid Waste Association (ISWA), Bonn/Geneva/Rotterdam.

Golev, A., Schmeda-Lopez, D., Smart, S., Corder, G. and McFarland, E. (2016). Where next on e-waste in Australia? Waste Management, $58,348-358$.

Hickey, S., Fitzpatrick, C., Mayer, P. et al. (2014). A case study of the D4R laptop. Waste and Resource Management, 167 (WR3), 101-108.

Higher Education Statistics Agency (2020). Where do HE students study? (Online) Available at: https://www.hesa.ac.uk/data-and-analysis/students/where-study (accessed 10 Feb 2020)

Kaiser, F.G., Hubner, G. and Bogner, F.X. (2005). Contrasting the Theory of Planned Behaviour with Value-Belief-Norm model in explaining conservation behaviour. Journal of Applied Social Psychology, 35(10), 2150-2170.
London Metal Exchange (2020). London Metal Exchange: Home. Available at www.Ime.com (accessed 23/5/2020

Martin, J. and Samels, J.E. (2012). The Sustainable University: Green Goals and New Challenges for Higher Education Leaders. The John Hopkins University Press, Baltimore, MD.

Martinho, G., Pires, A., Saraiva, L. and Ribeiro, R. (2012). Composition of plastics from waste electrical and electronic equipment (WEEE) by direct sampling. Waste Management, 32, 1213-1217

Massari, S. and Ruberti, M. (2013). Rare earth elements as critical raw materials: Focus on international markets and future strategies. Resources Policy, 38(1), 36-43.

Meloni, M. (2020). A circular economy for consumer electronics. In: Eduljee, G.H. and Harrison, R.M. (Eds), Issues in Environmental Science and Technology No. 49, Electronic Waste Management (2nd Edition). Royal Society of Chemistry Publishing. Available at https://pubs.rsc.org/en/content/chapter/9781788018784-00066/978-1-78801-878-4

National Council for Voluntary Organisations (NCVO). (2014). NCVO UK Civil Society Almanac 2014. Available at https://data.ncvo.org. uk/almanac14/.

OANDA (2020). Currency converter. Available at https://www1.oanda. com/currency/converter/.

Oguchi, M., Murakami, S., Sakanakura, H. et al. (2011). A preliminary categorisation of end of life electrical and electronic equipment as secondary metal resources. Waste Management, 31, 2150-2160.

Ongondo F.O. and Williams, I.D. (2011). Greening academia: use and disposal of mobile phones among university students. Waste Management, 31, 1617-1634.

Ongondo, F.O., Williams, I.D. and Cherrett, T.J. (2011). How are WEEE doing? A global review of the management of electrical and electronic wastes. Waste Management, 31 (4), 714-30.

Ongondo, F.O., Williams, I.D. and Whitlock, G. (2015). Distinct Urban Mines: Exploiting secondary resources in unique anthropogenic spaces. Waste Management, 45, 4-9.

Pierron, X., Williams, I.D., Shaw, P.J. and Cleaver, V. (2017). Using choice architecture to exploit a university Distinct Urban Mine. Waste Management, 68, 547-556.

Parajuly, K. and Wenzel, H. (2017). Potential for circular economy in housefold WEEE management. Journal of Cleaner Production, $151,272-285$.

Robinson, O.; Kemp, S. and Williams, I.D. (2015). Carbon management at universities: a reality check. Journal of Cleaner Production, 106, 109-118.

Robinson, O.; Tewkesbury, A.; Kemp, S. and Williams, I.D. (2018). Towards a universal carbon footprint standard: A case study of carbon management at universities. Journal of Cleaner Production, 172, 4435-4455.

Schultz, P.W., Oskamp, S. and Mainieri, T. (1995). Who recycles and when? A review of personal and situational factors. Journal of Environmental Psychology, 15, 105-121.

Shittu, O.S.; Williams, I.D. and Shaw, P.J. (2021). Global E-waste management: Can WEEE make a difference? A review of e-waste trends, legislation, contemporary issues and future challenges. Waste Management, $120,549-563$.

Stern, P.C. (2000). Toward a coherent theory of environmentally significantbehaviour. Journal of Social Issues 56, 407-424.

Tangwanichagapong, S., Nitivattananon, V., Mohanty, B. and Visvanathan, C. (2017) "Greening of a campus through waste management initiatives: Experience from a higher education institution in Thailand". International Journal of Sustainability in Higher Education, 18(2), 203-217.

Thaler, R.H., Sunstein, C.R. and Balz, J.P. (2010). Choice Architecture. Available at SSRN: https://ssrn.com/abstract=1583509 or http:// dx.doi.org/10.2139/ssrn.1583509.

University of Southampton (2019). Halls of residence (online) Available at: https://www.southampton.ac.uk/uni-life/accommodation/ halls.page (accessed 5 October 2019).

University of Southampton (2020). Our Sustainability Strategy (online) Available at: https://www.southampton.ac.uk/susdev/index.page (accessed 5 December 2020).

Vagnoni, E. and Cavicchi, C. (2015). An exploratory study of sustainable development at Italian universities. International Journal of Sustainability in Higher Education, 16, 217-236.

Waste and Resources Action Programme (2012). Electrical product material composition. (Online) Available at: www.wrap.org.uk (Accessed 20/3/2020). 
Waste and Resources Action Programme (WRAP) (2015). Resource Revolution: Creating the Future. Available at: https://www.wrap. org.uk/sites/files/wrap/WRAP-Plan-Resource-Revolution-Creating-the-Future.pdf [last accessed 21/07/2020].

Waste and Resources Action Programme (2020). Resource revolution: creating the future. (Online) Available at: http://www.wrap.org.uk/ about-us/our-plan (Accessed 20/3/2020).

WEEE Forum, The (2019): International e-waste day. (Online) Available at: https://weee-forum.org/iewd-about/ (accessed 4 Oct 2019).

World Economic Forum (2019). A new circular vision for electronics. World Economic Forum, 91-93 route de la Capite $\mathrm{CH}-1223 \mathrm{Co}$ logny/Geneva Switzerland; www.weforum.org.

Wilkinson, A. and Williams, I.D. (2020). Why do (W)EEE hoard? The effect of consumer behaviour on the release of (W)EEE from home entertainment products into the circular economy. Detritus (In press), 1-16 https://doi.org/10.31025/2611$4135 / 2020.14004$
Williams, I.D. (2015). A change of emphasis: waste to resource management, pp.207-252. In: Harrison, R.M., Hestor, R.E. (Eds.), Issues in Environmental Science and Technology No. 40. Still Only One Earth: Progress in the 40 Years Since the First UN Conference on the Environment. RSC Publishing, Cambridge. Print ISBN: 978-1-78262-0761. PDF elSBN: 978-1-78262-217-8. EPUB elSBN: 978-1-78262-644-2

Williams, I.D. (2016). Global Metal Reuse and Formal and Informal Recycling from Electronic and Other High-Tech Wastes. In: Metal Sustainability: Global Challenges, Consequences, and Prospects. 1 st ed. John Wiley \& Sons, 23-51.

Williams, I.D. and Powell, L. (2019). Sustainable resource management by students in higher education institutions. Detritus, 6, 11-24.

Zhang, L., Geng, Y., Zhong, Y. et al. (2019). A bibliometric analysis of waste electrical and electronic research. Environmental Science and Pollution Research, 26, 21098-21108 https://doi. org/10.1007/s11356-019-05409-2.

Zhang, N.,Williams, I.D. Kemp, S and Smith, N.F. (2011). Greening academia: developing sustainable waste management at higher education institutions. Waste Management, 31, 1606-1616. 